\title{
The embryoid development of Strigamia maritima and its bearing on post-embryonic segmentation of geophilomorph centipedes
}

\author{
Carlo Brena
}

\begin{abstract}
Background: Many arthropods add body segments post-embryonically, including most of the myriapods. However, geophilomorph and scolopendromorph centipedes are epimorphic, i.e. they form all their segments during embryonic time, although this has never been demonstrated directly. Understanding the similarity between embryonic and post-embryonic segmentation is pivotal to understand the possible evolution from anamorphosis to epimorphosis. We have previously demonstrated that in the geophilomorph centipede Strigamia maritima most segments are produced by an oscillatory mechanism operating through waves of expression at double segment periodicity, but that the last-forming (posteriormost) segments are patterned with a different system which might be more similar to post-embryonic segmentation.

Results: With a careful analysis of a large number of specimens, I show that the first ("embryoid") phase of post-embryonic development is clearly distinct from the following ones. It is characterized by more moults than previously reported, allowing me to define and name new stages. I describe these embryoid stages and the first free-leaving stage in detail, providing data on their duration and useful identification characters. At hatching, the prospective last leg-bearing segment is limbless and the genital segments are added in the following stages, indicating a residual anamorphosis in Strigamia segmentation. I demonstrate directly for the first time that at least the leg-bearing segments are in general produced during embryonic life, although in some individuals the external delineation of the last leg-bearing segment may be delayed to post-embryonic time, a possible further residual of anamorphic development. Additionally, I show that the development of the poison claws during this post-embryonic phase may have some element of recapitulation.

Conclusions: The data presented in this paper show that the embryoid phase of post-embryonic development of geophilomorph centipedes may represent an extension of embryonic development, possibly in correlation with the evolution of epimorphic development from an anamorphic ancestor, accomplished without completely losing post-embryonic segmentation activity. This continuity in the segmentation process across the embryonic/ postembryonic divide may concur to the evolvability of this developmental process.
\end{abstract}

Keywords: Myriapods, Chilopod, Staging, Post-embryonic, Epimorphosis, Anamorphosis, Arthropod evolution, Forcipule, Recapitulation

Correspondence: carlobrena@hotmail.com

Laboratory for Development and Evolution, Department of Zoology,

University of Cambridge, Downing Street, Cambridge CB2 3EJ, UK 


\section{Introduction}

Metamerism is a key morphological character of arthropods. To understand its evolution, it is fundamental to understand how this reiteration of modules along the anteroposterior (AP) axis is laid down during development. In the great majority of arthropods with a high number of segments, these are mostly formed post-embryonically, differentiating from a mass of posterior undifferentiated tissue, with the process not being visible externally from the morphology of the exoskeleton. On the contrary, the first segments of those arthropods - and all segments in arthropods like the insects - are laid down embryonically through a molecular patterning process that can precede any morphological differentiation. This process extends to several segments (sequentially segmenting arthropods) or even to all segments (long germ arthropods like Drosophila). It is not clear whether this embryonic process is in continuity with the post-embryonic phase of segmentation, and if so to what extent, although understanding this would be pivotal to understanding the evolutionary transition from anamorphosis to epimorphosis.

Geophilomorph centipedes are the only arthropods with a high and, in most cases, intraspecifically variable number of segments (up to 191 leg-bearing segments, LBS) known to form all of their segments embryonically [1] (but see below). Geophilomorphs are epimorphic as are their sister group, the scolopendromorphs, although the latter have an intraspecifically-invariant and smaller number of segments (21-23 LBS) (with two exceptions [2,3]). This is in contrast with the other centipedes, or Chilopoda (Craterostigmomorpha, Lithobiomorpha and Scutigeromorpha) and all other myriapods (Symphyla, Pauropoda and Diplopoda, or millipedes) all of which have anamorphic development, with some, or, in the case of the majority of millipedes, most of the segments formed post-embryonically. The epimorphic nature of development has been always considered a well defined trait of Geophilomorpha and Scolopendromorpha and has been recognised as a major apomorphy, to the extent that their clade is called Epimorpha. Understanding how this character has evolved and fixed represents a major step towards understanding the evolution of the clade.

I have been studying Strigamia maritima as a representative of the geophilomorph centipedes. In these centipedes the many segments laid down along the whole germ band are fully available for molecular and developmental analysis as a whole. Recent studies [4] have confirmed that the great majority of these segments are originally produced as morphogenetic units by a sort of segmentation clock, through a cycling activity of segmentation genes operating by waves of expression acting at a double segment periodicity. In contrast, the last part of the segmentation process, although in continuity with the main one and involving most of the same genes, is associated with a change in the molecular process. Here single segmental molecular patterning appears periodically at the anterior margin of the still active growth zone, where conditions are definitely more static and patterning of the localized undifferentiated tissue appears to be associated more with cell proliferation [4]. These conditions might be more similar to the ones which characterise postembryonic segmentation.

In fact, the embryonic/post-embryonic divide is a problematic issue per se. Indeed, it is clear that at hatching, a geophilomorph centipede is little more than an embryo without an egg shell, still brooded by the mother for an additional long period. In this animal, the rupture of the egg chorion does not represent a clear-cut change from an embryonic to a post-embryonic state $[5,6]$. These nonfeeding post-embryonic stages reside with the mother, who stays coiled around them in the brood chamber, a small cavity in the soil matrix. All these brood stages have been termed 'larval stages' by several authors [7-9] (in particular Lewis in his review book [10]) to distinguish them from the later juvenile instars ('post-larval stages', in Lewis' terms). (In this paper I will use the term 'juvenile' as a generic term to indicate all post-embryonic immature stages). The use of the term 'larva' to describe these brooded stages is highly debatable, and I agree with Minelli and Fusco [11] in suggesting that we should be cautious using this word. I refer to them for a comparative discussion on this topic throughout the arthropods. Consequently, I will call these early post-embryonic stages (proembryoid I to III, peripatoid, foetus; see below) 'embryoid', a term already used for similar instars in several arthropods (see e.g. [11]), because of their similarity with actual embryos. Post-embryoid stages start with the first freeliving and feeding stage, the adolescens I, which leaves the mother some time after the moult and has most of the adult characters.

Besides earlier accounts [12-15], the first proper description of these embryoid stages was provided by Verhoeff [16], describing two stages: a peripatoid and a foetus, and those terms have been used in subsequent studies on different species (e.g. [7-9,17,18]). As far as development is concerned, Strigamia maritima is by far the best described geophilomorph species. Yet, while we have a reasonably good description of the postembryoid stages and their timing [18-20], previous attempts to describe in part [20] or specifically [21] these early post-embryonic stages have somehow failed to recognise the number and timing of moults precisely, leading to some confusion and inconsistency in recognising, describing, or naming the stages, an issue which is common to the whole of Geophilomorpha.

To try to better understand and define it, I carried out a detailed analysis of this phase of post-embryonic development, based on the improved techniques of culturing eggs and juveniles in mineral oil [22]. This analysis follows up 
published work on the embryonic development of Strigamia maritima where we have defined, described and timed the several stages [6]. Following a rather traditional approach, in this paper I will use a moult, or more precisely an ecdysis, i.e. the actual shedding of the exuvia, as a well defined, recognisable and, most importantly, discontinuous point in time to define the passage from one stage to another. Nevertheless, I do not consider it necessarily a major overall change in the developmental state of the whole animal, as we have previously pointed out [5] (see [11] for a more detailed account and general discussion on the use and definition of the word 'stage').

My analysis has allowed me to identify three previously undescribed moults and their associated embryoid stages, thus I present here a better description of known stages and their timing of development covering the previous gap of information between embryonic and later juvenile stages. This should help understand the transition between these two phases both in development and in evolution.

While analysing specimens for descriptive reasons during their larval development, I found an individual that was apparently still adding leg-bearing segments. Based on weak evidence, some authors have claimed that a few segments might be added after hatching [23,24], although other authors have dismissed that claim $[8,25,26]$. In fact, all these studies are based on indirect evidence, mostly analyzing the distribution of segment number between different age classes or based on the lack of germinal tissue in late embryoid stages. Indeed, the epimorphic nature itself of segment formation in geophilomorphs, although always assumed to be a fact, has never been based on direct observations on the very first post-embryonic stages. Published data cannot rule out the possibility of an occasional delaying of segment formation into the post-embryonic phase. This possibility may be rather important from an evolutionary point of view, as it would show the potentiality for a shift from one segmentation mode to another. To try to identify this possibility, I have followed a workably high number of specimens individually through the embryoid stages to check whether there was any addition of segments.

Considering that this study is based on the analysis of live specimens, I should stress that, in general, 'segment' in this paper means an identifiable subdivision of the cuticle, externally recognisable as a full serial unity along the antero-posterior (AP) axis of the animal. This in fact is the standard approach when defining the number of segments, for example, of the different instars of anamorphic myriapods, independent of the more advanced state of development of the internal metameric tissues or organs.

I have found that almost no individual added legbearing segments after hatching, although a very small fraction have delayed the complete production of the last leg-bearing segment. In any case, all specimens added the two genital segments during embryoid (postembryonic) development. On one hand, this has confirmed, directly for the first time, the general epimorphic nature of leg-bearing segment addition in Strigamia. On the other hand, though, it has shown that indeed a small remnant of anamorphic segmentation is still present.

\section{Results}

\section{Embryoid stages in Strigamia}

The following description of stages is based on the best conditions under which live embryoid specimens can be observed, i.e. immersed, mostly in mineral oil, with their exuviae artificially removed. Those exuviae will stay attached to the rear end of the animal in any culturing conditions, although it is not clear when and how exactly the young Strigamia dispose of them in nature and if and how the mother helps them. Although described by previous authors [18,21], I don't think movement of any kind can be a real discriminatory trait between stages. Indeed, there is a continuum in the acquisition of motility of Strigamia embryoids, from the strong peristaltic movement already present in late embryonic stages [6] to writhing movements in late foetus stages. Moreover, presumably there is an increase of this activity within a single stage, as the animal gets older.

It is impossible to define a general state of development of a generalized leg (i.e. a leg representative of trunk segments), because from the appearance of the first segment during embryonic development to the last embryoid stage there is a smooth gradient in the level of development along the animal's AP axis. This implies that it is equally impossible to define precisely how many final legs are in a given state of development, e.g. externally segmented as in proembryoid III (see below).

Given my introduction of new early stages and the inconsistency of previous descriptions, I have decided to use the known term 'peripatoid' for the longer stage preceding the foetus stage, in accord with [27].

See Table 1 for the defining characters of each embryoid and adolescens I stage.

\section{Hatched stage 8 embryo Approx duration: 2 days}

Strigamia eggs hatch after approximately 48 days at $13^{\circ} \mathrm{C}$, a temperature close to the average June temperature at the field site for this population [6]. The rupture of the chorion is probably promoted by internal pressure and by movements of the embryo which are characteristic of the last embryonic stage (8) [6]. The opening is presumably triggered by the action of the so called 'egg tooth': this is a sharp sclerotised tip on the embryonic cuticle of the second maxillae. The cuticle is already free, as the apolysis 
Table 1 Summary of the defining characters of early post-embryonic stages in S. maritima: embryoid stages (Proembryoid I to Foetus) and first free living juvenile stage (adolescens I) (ec: embryonic cuticle)

\section{Strigmia marittima embryoids and adolescens I STAGING TABLE}

\begin{tabular}{|c|c|c|c|c|c|}
\hline Stages & Shape of the body/trunk & Last leg-bearing segment & Genital segment(s) & Antennae & Additional characters \\
\hline \multicolumn{6}{|l|}{ Ecdysis ec } \\
\hline Proembryoid I & $\begin{array}{l}\text { Sharp angle between anterior and } \\
\text { posterior trunk anterior half much } \\
\text { larger, with ventral side concave }\end{array}$ & Limbless & $\begin{array}{l}\text { terminal trunk } \\
\text { undifferentiated, } \\
\text { barely developed }\end{array}$ & $\begin{array}{l}\text { Ventral (slightly anterior), } \\
14 \text { unclear antennomeres, } \\
\text { depressed }\end{array}$ & \\
\hline \multicolumn{6}{|l|}{ Ecdysis e1 and e2 } \\
\hline Proembryoid II and III & $\begin{array}{l}\text { Angle between anterior and } \\
\text { posterior trunk anterior half } \\
\text { slightly larger, with ventral } \\
\text { side flat }\end{array}$ & Limb buds just appearing & $\begin{array}{l}\text { terminal trunk } \\
\text { undifferentiated, } \\
\text { extended }\end{array}$ & $\begin{array}{l}\text { Ventral orthogonal, } 14 \\
\text { antennomeres slightly elongated }\end{array}$ & \\
\hline \multicolumn{6}{|l|}{ Ecdysis e3 } \\
\hline Peripatoid & $\begin{array}{l}\text { Uniform circular section } \\
\text { of trunk along AP axis }\end{array}$ & $\begin{array}{l}\text { Limb buds extended but } \\
\text { barely, if not, segmented }\end{array}$ & $\begin{array}{l}\text { single genital segment } \\
\text { defined (single segmental } \\
\text { furrow present) }\end{array}$ & $\begin{array}{l}\text { Ventral forward more than } \\
90 \text { degrees from the main } \\
\text { head/trunk axis, } 14 \text { well } \\
\text { defined antennomeres }\end{array}$ & \\
\hline \multicolumn{6}{|l|}{ Ecdysis e4 } \\
\hline Foetus & $\begin{array}{l}\text { Trunk slightly dorsoventrally } \\
\text { depressed }\end{array}$ & $\begin{array}{l}\text { Limbs segmented, although } \\
\text { less developed than the } \\
\text { rest of the legs }\end{array}$ & $\begin{array}{l}\text { subdivision in segments, } \\
\text { but number and shape } \\
\text { unclear because not } \\
\text { clearly defined }\end{array}$ & $\begin{array}{l}\text { Elongated and divaricated } \\
\text { further, extending forward, } \\
\text { almost on the trunk plane }\end{array}$ & $\begin{array}{l}\text { Appearance of setae, maxillipeds/ } \\
\text { forcipules tanned and } \\
\text { multisegmented }\end{array}$ \\
\hline Adolescens I & Trunk dorsoventrally depressed & $\begin{array}{l}\text { Legs fully differentiated } \\
\text { but distinguished from } \\
\text { the rest of the legs }\end{array}$ & $\begin{array}{l}\text { differentiated with several } \\
\text { sclerites in two genital } \\
\text { segments and terminal } \\
\text { anal valves }\end{array}$ & $\begin{array}{l}\text { Tanned in stripes, rich } \\
\text { in setae and sensilla }\end{array}$ & $\begin{array}{l}\text { Well developed and abundant setae, } \\
\text { tanning in particular of head and } \\
\text { forcipular segment }\end{array}$ \\
\hline
\end{tabular}


has started already at the transition between stage 7 and 8 of embryonic development [6] (Figure 1A,B,B1). Under culture conditions, the chorion of some eggs does not open; in this case those embryos, although constrained and not able to extend, will somehow continue development for a while within the intact chorion, going through several moults (data not shown).

In general, the chorion is not fully shed, and at least half of it may stay attached to the posterior end of the animal for several stages (see below). The hatched specimen is basically the stage 8 embryo, with the embryonic cuticle (ec in Figure 1) still covering the whole body but largely detached (see on the tip of antennae in Figure 1B1). The animal is still fully folded in two by the dorso-ventral flexure, head facing the proctodeal opening, with the juxtaposed anterior and posterior halves of the ventral side still apparently kept in position by lateral cuticle extensions (see [6]).

After a couple of days, the embryo starts undergoing ecdysis, cracking the embryonic exuvia just posterior to the head. Once detached, this exuvia shows the entire ectoderm pattern associated with the stage 7 embryo, including the undifferentiated ectoderm covering the surface dorsal to the hemitergites (htb in Figure 1C1), which have not yet extended to complete dorsal closure. Once joined, the left and right hemitergites will give rise to the full tergite, as seen in the proembryoid I ( $t$ in Figure 1D) (see [27] for full description).

Throughout this stage, and indeed from before hatching, the gut of the animal shows extensive peristaltic contractions which redistribute the mass of pink pigmented yolk contained within it (see Additional file 1: movie 1). This
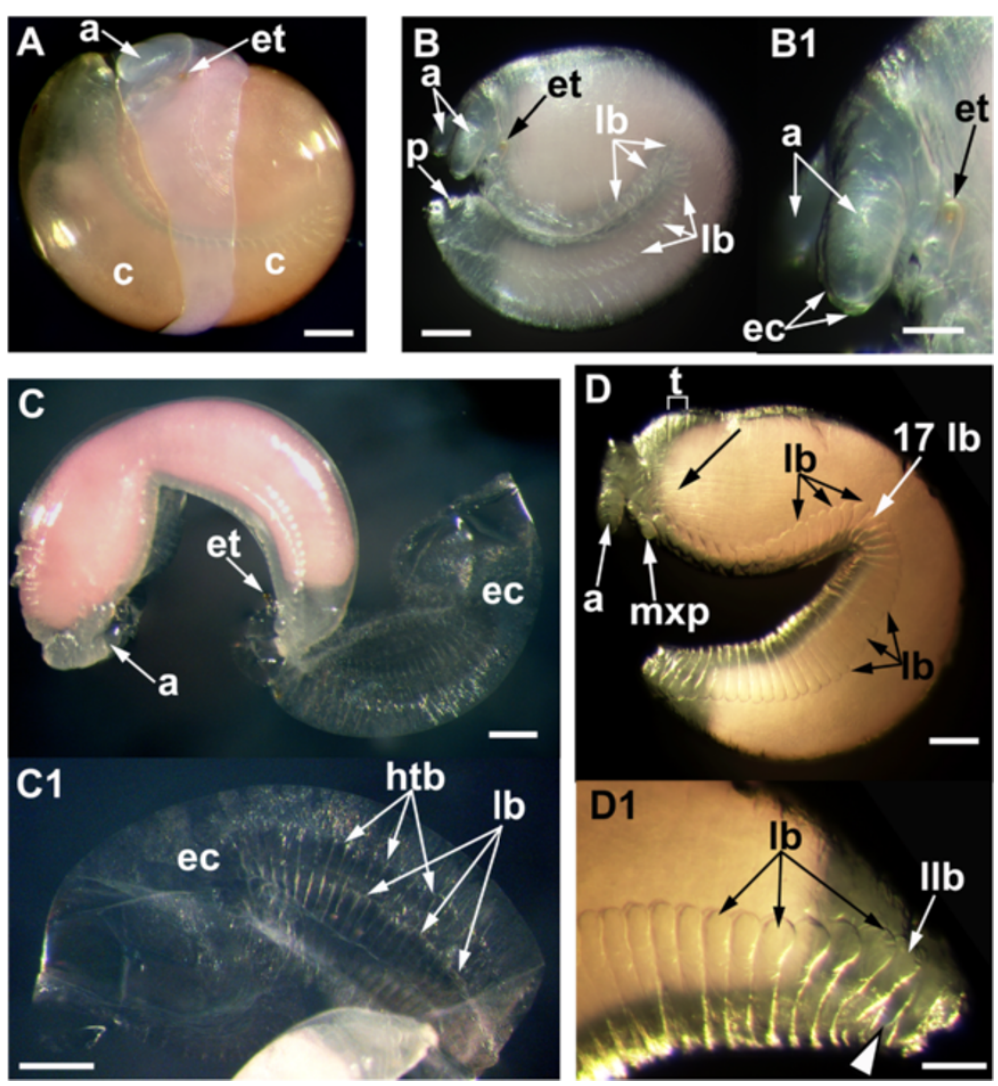

Figure 1 Hatched egg and proembryoid I. Lateral view; live specimens immersed in LES (A-C) or in mineral oil (D). In this figure anterior is to the left and the dorsal side is to the top, at least for the anterior half of the animal (see Figure 2 in [27] to better understand orientation). Panels with the same letter indicate different views of the same specimen. (The same conventions apply to all other figures, unless stated otherwise). A: Hatched egg showing what is essentially a final (late stage 8) embryo lying within the cracked chorion (c). B: Hatchling of the same stage with the chorion manually removed. B1 is a high magnification of $\mathbf{B}$, showing in more detail the egg tooth (et) on the second maxillae, which is used to crack the chorion. Note that the embryonic cuticle (ec) on the antennae (a) has already detached from the underlying epithelium (i.e. apolysis has occurred). C-D: proembryoid I, just after moulting in C, with the embryonic cuticle (ec) still attached to the rear of the animal; this exuvia has been manually removed in $\mathbf{D}$. C1: the detached exuvia showing all cuticular traits as laid down in stage 7 embryo. The proembryoid I is still sharply folded at the level of the $17^{\text {th }}$ LBS. The limb buds (lb) appear as lateral protrusions of the ventral segmental units, and are differentially developed along the anteroposterior axis, from the more differentiated antennae (a) to the last formed segment (eventually the last leg-bearing segment), which lacks the limb buds altogether. D1 is a higher magnification of the specimen in D, turned upside down. htb: semicircular dorsal border of the hemitergites; llb: last limb bud; mxp: maxilliped; p: proctodeum; t: tergite. Scale bars: A, B, C, C1, D: 200 m; B1, D1: 100 m. 
movement and the associated contraction of the whole body may promote the following ecdysis (see Additional file 2: movie 2).

\section{Proembryoid stages}

I introduce the term 'proembryoid' to describe the very first post-embryonic stages, unrecognised by previous authors. This phase is characterized by two ecdyses, with the third ecdysis giving rise to the following peripatoid stage. Those two ecdyses happen in a short interval, to the extent that the second one starts at the anterior part before the first is completed at the posterior part (see Figure 2). The near simultaneity of these two ecdyses did not allow for the characterization of the stage between them, as I could directly observe only stages proembryoid I and proembryoid III. For this reason, proembryoid stages II and III will be discussed together. Finer future studies may provide discriminating traits between proembryoid II and III.

\section{Proembryoid I}

\section{Approx duration: 2 days}

This stage basically corresponds to the last embryonic stage 8, without the embryonic cuticle (the ecdysis of which starts at the beginning of embryonic stage 8 [6]) and with the yolk in the gut still occupying most of the internal volume. The anterior half is still markedly larger than the posterior one. The anterior and posterior halves of the ventral surface are now well separated and form a rather sharp angle. This position seems to be rather fixed and in general not correlated with the variable final number of segments. Indeed, in $85 \%$ of cases $(n=66)$, the limb bud just before or in the middle of the bending point belongs to the 17th LBS (the 16th in 6\% and the 18th in $9 \%$ of cases). In particular, there does not seem to be a correlation between this position and the sex of the animal, as among those with the bending at the 17th LBS, 50\% have 47 LBS and 50\% 49 LBS, mirroring the expected 50:50 sex ratio of the Brora population where $86 \%$ of the animals are either males with 47 LBS or females with 49 [28]. Having said that, some very minor, but consistent, correlations may be present at a finer level, as the 17 th limb bud precedes the bending point in $46 \%$ of the specimens with total 47 LBS and only $8 \%$ of those with 49 LBS total. Additionally, extreme lower values at the bending point never correspond to a high value of total LBS number (there is no 16th LBS at the bending point in specimens with a total of 49 or 51 LBS and no 18th at the bending point in specimens with total 45 LBS).

The developmental gradient along the AP axis is particularly evident, in particular in the development of the limb buds. In this sense, most of the anterior limb buds including the antennae, maxillae and maxillipeds (forcipules) show a good degree of segmentation (Figure 1D), while the most posterior limbs are just unsegmented buds. In live material and in my preparations it is difficult to ascertain the specific number of segments in the limbs, but at least the antennae appear to be articulated into their final
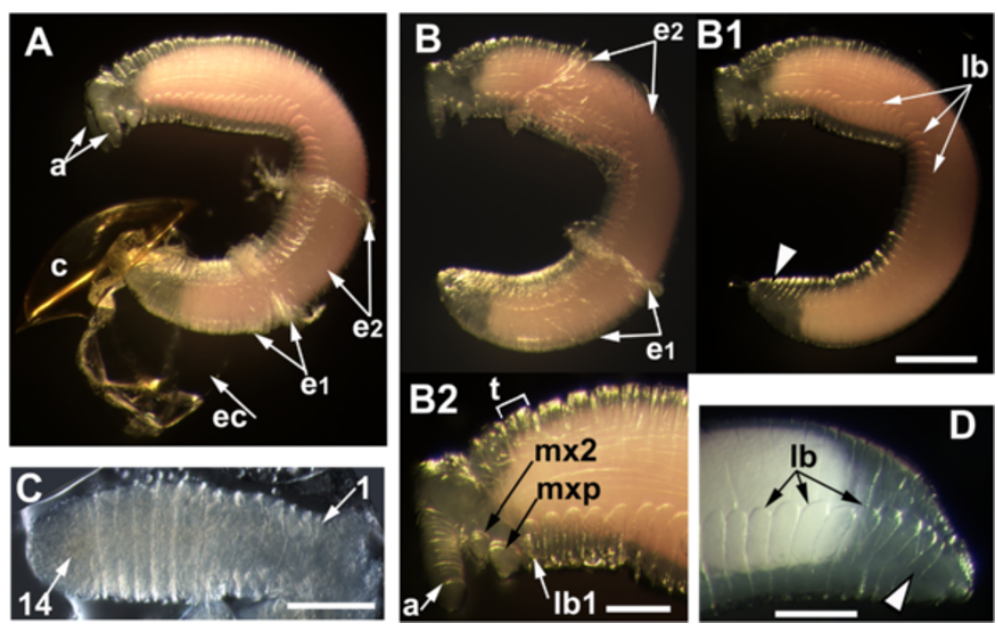

Figure 2 Proembryoid II and III. A, B, D: Lateral views; live specimens immersed in mineral oil; C: unfixed preparation mounted on a slide and viewed at the compound microscope with Nomarski optics. A: the proembryoid III has partially shed the II exuvia (e2) while the embryonic cuticle (ec) and the chorion (c) are still attached at the rear end of the animal and the proembryoid I exuvia (e1) still covers part of the trunk, overlying the e2 exuvia. In B the chorion and embryonic cuticle, and in B1 also the proembryoid I and II exuviae (e1, e2) have been removed to show all limb buds (lb) of the proembryoid III stage. The limb buds of the last LBS is now visible (arrowhead); note that the specimen in $\mathbf{B}$ is slightly younger than the one in $\mathbf{A}$, with the e2 exuvia still covering most of the trunk. B2: high magnification of $\mathbf{B}$, showing the extent of differentiation of the most anterior limbs including the antenna (a), second maxilla (mx2), maxilliped (mxp), first leg (lb1) and the tergite (t). $\mathbf{C}$ : high magnification of an antenna, showing the differentiation of all 14 antennomeres. $\mathbf{D}$ : high magnification of terminal part of the trunk, showing the initial development of the last limb bud (arrowhead). Scale bars: A, B, B1: $500 \mu \mathrm{m} ;$ B2, D: $200 \mu \mathrm{m}$; C: $100 \mu \mathrm{m}$. 
number of 14 antennomeres (Figure 1D). The most noteworthy fact is that the last formed segment, which will be eventually the last LBS, is limbless at this stage (arrowhead in Figure 1D1). Posterior to that segment, genital segment (s) are not developed yet, at least at the level of the cuticle/ external morphology and general extension of the region.

\section{Proembryoid II and III Approx duration: 4 days}

By this stage the animal has dramatically extended, mostly thanks to the elongation of the posterior part with all segments along the body now with similar extension. The anterior part of the body is only slightly larger than the posterior one. The midgut with the yolk in its lumen starts to retract from the posterior end of the trunk. If not manually removed, the first three exuviae, i.e. the embryonic cuticle and proembryoid I and II exuviae (ec and e1-2 in Figure 2) are still covering a decreasing part of the animal (Figure 2A). The anterior part of the trunk is now almost straight ventrally and the sharp angle between it and the posterior part is reduced. The differentiation of the tergites into pretergites and metatergites is now well marked.

Segmentation of the anterior limbs is further developed and by now the final number of 14 antennomeres can be precisely identified (Figure 2B2 and C), although the antennae as a whole are only slightly elongated in comparison with the previous stage. The antennae form now a $90^{\circ}$ angle with the major head axis. The few last limbs are still un-segmented and the very last leg buds has now just started to develop as a lateral protrusion of the ventral portion of the last LBS (arrowhead in Figure 2B1 and D). The genito-anal area of the trunk is now more extended but no subdivision of the cuticle is recognizable.

\section{Peripatoid \\ Approx duration: 4 days}

The peripatoid appears after the 4th ecdysis, and all 4 exuviae tend to remain attached to the rear of the animal, each included in the previous one, hence requiring manual removal to get the entire body clean (Figure 3A).

The trunk is now elongated, with a roughly circular cross-section, more or less uniform along the AP axis (Figure 3B). The antennae extend ventrally forward more than 90 degrees from the main head/trunk axis. The antennomeres are now very distinct. The second maxillae start to differentiate the telopodite, while the maxillipeds, faintly multi-segmented, present a sharp tip (Figure 3C). Legs up to mid-trunk show a good level of differentiation, although the identity of the single podomeres is unclear (Figure 3D). The last leg buds are still almost unsegmented (Figure 3E). For the first time a clear cuticle furrow defines a genital segment (Figure 3E).

\section{Foetus}

\section{Approx duration: 28 days}

At this stage the embryoid has further elongated, shows more defined/separated trunk segments and starts to be slightly compressed dorso-ventrally (Figure 4A,C). Foregut and hindgut, which lack the pink yolk confined to the midgut, are more extended, but their extension depends on the age of the animal and probably on the state of body contraction of the specimen (compare Figure 4A with Figure 4C).

The antennae, further elongated and divaricated, now extend forward, almost in the same plane as the trunk (Figure 4A-C). The maxillipeds, extended forward at a $45^{\circ}$ angle, are now properly developed, with extended, sclerotized and partly tanned tips; they appear to be constituted by up to 7 segments, although the precise number and identity of forming podomeres is far from clear in my preparations (Figure $4 \mathrm{~B}$ and Additional file 3: Figure S1). Segmentation of most of the legs is now well defined at the cuticular level and, although of similar length, the different podomeres have reached their final number and can be tentatively distinguished as coxa, trochanter, prefemur, femur, tibia, tarsus and a final claw (or pre-tarsus) (Figure 4D, the coxa is not distinguishable here). The first small setae appear, although they are clearly visible only with careful focusing at the microscope, in particular on antennae and limbs (they are barely visible around the tip of the prospective pre-tarsus in Figure 4D). The terminal legs, although less developed, are now clearly segmented. The genital segment(s) is further developed, although a subdivision of the cuticle into more segments or segmental structures is not clearly detectable (Figure 4E). In cultured specimens, all 5 exuviae and the chorion can still be attached to the rear of the animal (Figure 4F see also Figure $1 \mathrm{C}$ in [5]) but not when the embryoids are in the brood chamber with the mother (Figure 4G-H), which may indicate her active role in disposing of those materials. Foetuses tend to show pronounced writhing movements, both in immersion in mineral oil (Figures 4A-C), and in their brood chamber (Figure 4H).

\section{Adolescens I \\ Beginning around 40 days after hatching}

With the 6th moult, the animal has now all the characters that in a more developed state will typify the adult. The trunk is dorsoventrally depressed with well developed legs extending laterally. The juvenile is very active, contracting in twisting movements in immersion (Figure 5A); in these conditions, the animal survives for only few days. The cuticle, although mostly transparent, is relatively well sclerotized and starts to be tanned. Particularly tanned is the cuticle of the head and of the first trunk segment, i.e. the forcipular segment (Figure 5A,C-F). Gnathal limbs are 

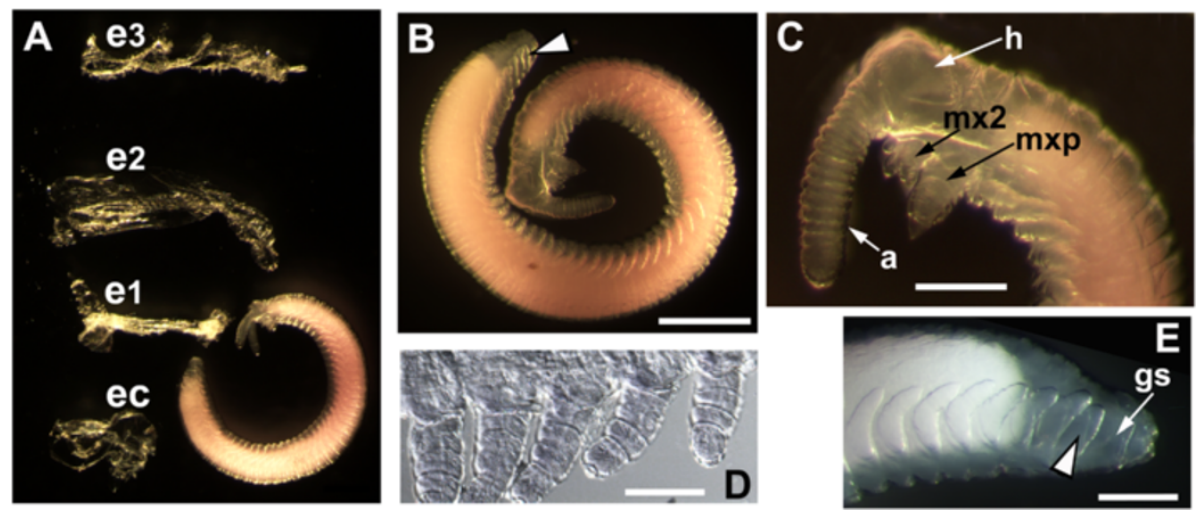

Figure 3 Peripatoid. A, B, C, E: Lateral view; live specimens immersed in mineral oil. D: unfixed preparation mounted on a slide and viewed at the compound microscope with Nomarski optics. A: specimen with its 4 manually removed exuviae (the embryonic cuticle, ec, and the three proembryoid exuviae, e1-3) originally attached to the rear end of the animal; $\mathbf{B}$ : the peripatoid tends to keep a coiled position with the head in proximity of the posterior end of the animal; all limb buds are more or less developed up to the last one (arrowhead); $\mathbf{C}$ : high magnification of head ( $h$ ) and anterior trunk showing elongation of the antennae (a) and development of second maxillae (mx2) and maxillipeds (mxp); note that in this specimen the apolysis of the next moult has already taken place in some anterior regions, as shown by the detachment of the cuticle from the tip of the maxillipeds. D: high magnification of mid-trunk limbs showing clear signs of segmentation of the cuticle, although the identification of single podomeres is not possible; E: high magnification of the terminal part of the trunk, showing the initial development of the last limb buds (arrowhead) and a clear delineation of a genital segment (gs). Scale bars: A, C: $500 \mu \mathrm{m} ;$ B, E: $200 \mu \mathrm{m} ;$ D: $100 \mu \mathrm{m}$.
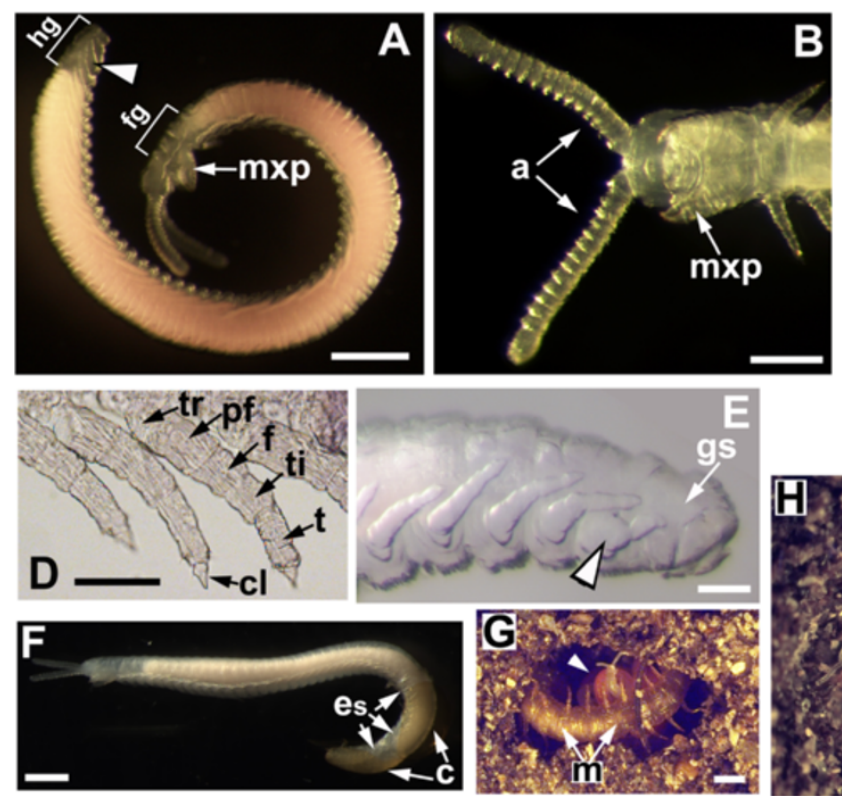

E
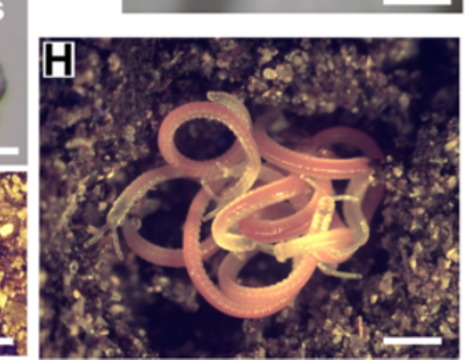

Figure 4 Foetus. Specimens immersed in mineral oil (A, B, C, E: alive; F: dead); A, C, E, F: lateral view; B: ventral view; D: unfixed preparation mounted on a slide and viewed at the compound microscope with Nomarski optics. $\mathbf{A}$ : The foetus tends to contract, putting the head close to the posterior end of the animal; all legs are developed, including the last one (arrowhead); maxillipeds (mxp) stretch forward ventrally; brackets show extension of foregut (fg) and hindgut (hg); $\mathbf{B}$ : high magnification of the head (a: antennae; mxp: maxillipeds); C: specimen with light-coloured background, to get a more natural appearance, including the brownish tip of the maxillipeds (mxp); $\mathbf{D}$ : high magnification of mid-trunk legs with tentative identification of podomeres (tr: trochanter, pf: prefemur, f: femur, ti: tibia, t: tarsus, cl: final claw); $\mathbf{E}$ : high magnification of the terminal part of the trunk, showing the last leg (arrowhead), by now partially developed and segmented, and the genital segment (gs) (the wrinkled aspect of the last legs is probably a culturing condition artefact); $\mathbf{F}$ : specimen in which chorion (c) and exuviae (es) have not been removed but still cover the terminal part of the trunk; G: window on the beach matrix, partially showing a brood chamber: the mother $(\mathrm{m})$ is still coiled around a brood of foetus juveniles (arrowhead) with her ventral surface facing outside; $\mathbf{H}$ : brood of foetus juveniles of panel $\mathrm{G}$ once the mother has escaped following the opening of the brood chamber. Scale bars: $\mathbf{A}, \mathbf{C}, \mathbf{F}$ $500 \mu \mathrm{m} ; \mathbf{B}: 300 \mu \mathrm{m} ; \mathbf{D}, \mathrm{E}: 100 \mu \mathrm{m} ; \mathbf{G}, \mathbf{H}: 1$ mm. 

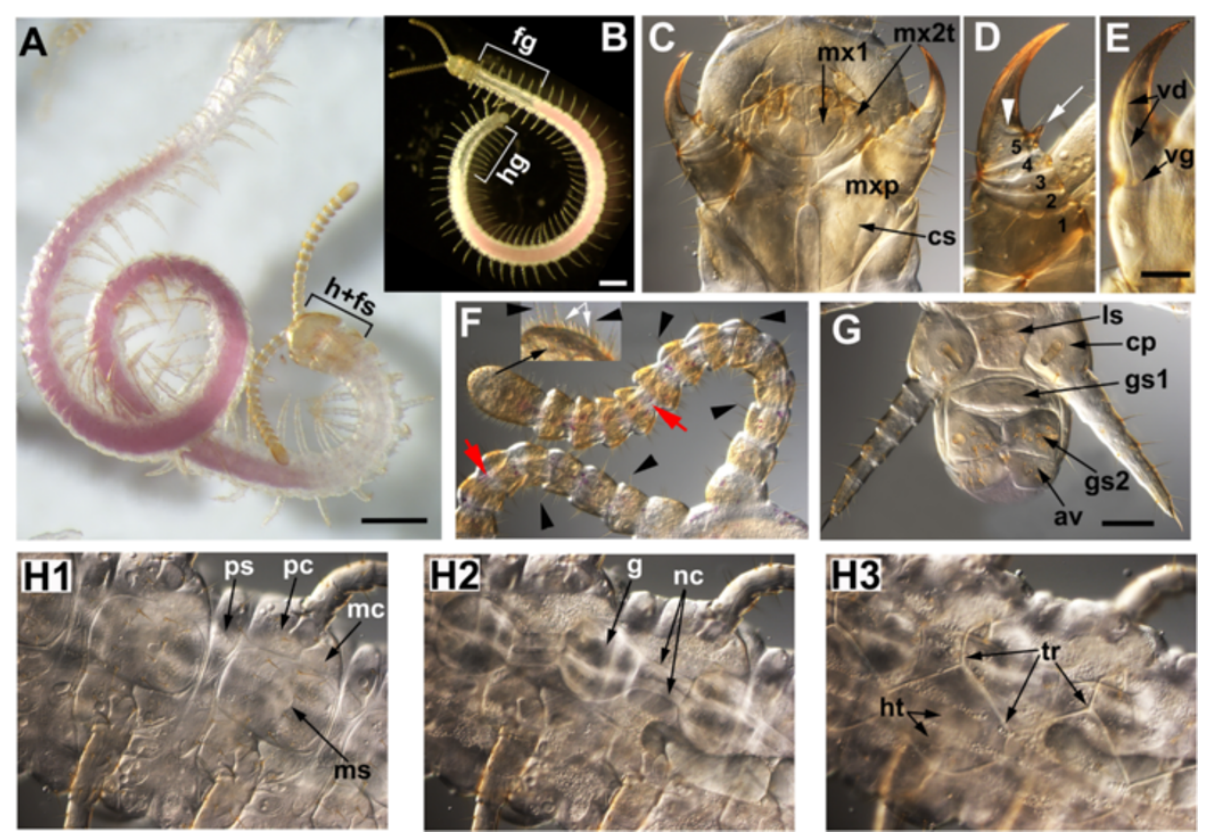

Figure 5 Adolescens I. A, B: live specimens in mineral oil, dorsal view; C-H: unfixed specimens viewed at the compound microscope with Nomarski optics, ventral view. A: adolescens I, showing typical torsion movements, viewed on white background to highlight the tanning of the head cuticle ( $\mathrm{h}$ ) and maxilliped/forcipular segment (fs) and intensity of yolk pink pigment associated with the mid-gut. B: specimen showing relative extension of foregut ( $\mathrm{fg}$ ) and hindgut (hg). C: high magnification of the head, showing complete differentiation of the gnathal limbs: first maxillae $(m \times 1)$, second maxillae ( $m \times 2$ t: telopodite of the second maxillae) and forcipules/maxillipeds (mxp). $\mathbf{D}$ : in addition to the coxosternite ( $c s$ in $\mathbf{C}$ ) the forcipule appears to be composed of additional 5 articles (1-5) (see text for details); E: middle focal plane of a forcipule showing venom duct (vd) and venom gland (vg); F: high magnification of the antennae covered by setae (arrowheads) and, on the last antennomere, also by basiconic sensilla (white arrows in the high magnification insert); muscle fibres are visible along the main axis (red arrows); G: high magnification of the terminal segments of a female, showing the sternites of the last LBS (Is) and of the first (gs1) and second genital segment (gs2), followed by the anal valves (av); appearance on the surface of the coxal pore (ср) canal is an artefact of focal planes stacking; $\mathbf{H}$ : high magnification of mid trunk, viewed at different focal planes, progressively away from the viewer $(\mathrm{H1}, \mathrm{H2}, \mathrm{H3})$; $\mathrm{H1}$ : surface focal plane, with metasternite (ms), presternite (ps), metacoxa (mc) and procoxa (pc); H2: focal plane just under the surface with double nerve cord (nc) and ganglia (g); H3: focal plane just below the dorsal surface, with heart (ht) and tracheae (tr). Scale bars: A, B: $500 \mu \mathrm{m} ;$ C, F-H: $100 \mu \mathrm{m}$; D-E: $50 \mu \mathrm{m}$.

developed with their specific components, e.g. the telopodites of the second maxillae, and hence should be by now fully functional (Figure 5C). In particular, the maxillipeds/forcipules are well developed, and each appears to be constituted by a basal large coxosternite (cs in Figure $5 \mathrm{C}$ ), and 5 other segments (1-5 in Figure 5D), although I don't know whether there is articulation between all of them. This subdivision has been more or less clearly observed in all good quality flat-mounted preparation of adolescens I $(n=20)$. The identification of the individual articles is uncertain because in the adult they are only 4 (see Discussion). I tentatively interpret them as being 1: trochanter, 2: prefemur, 3: femur, 4: tibia, and 5: tarsungulum, the latter with its well formed denticle (arrow in Figure 5D) (a character found in many geophilomorph lineages) and transverse sulcus (arrowhead in Figure 5D). The forcipules are equipped with a venom gland with its well-formed duct, opening close to the tip of the claw (Figure 5E). Judging from the intensity of the pink colour, the midgut is still rather full of yolk, but the transparent foregut and hindgut are now much more extended than in previous stages (Figure 5A-B).

The antennae, provided with muscle fibres all along their length, are covered with setae, the last antennomere with small basiconic sensilla as well. The antennae show a pattern of alternating bands due to the partial tanning of the cuticle within each antennomere (Figure 5F).

The last legs are now fully developed as the other ones, but with some peculiarities, particularly the coxae, enlarged and provided with a single coxal pore at its centre (Figure 5G); those legs appear already at this stage not be used for walking, although they are not yet sexually differentiated as they are in the adult (see [29]). The terminal area is now for the first time completely differentiated into two genital segments and terminal anal valves; in males the sternite of the first genital segment starts to differentiate two medio-lateral protusions (see also [20,22,29]), which will become the two gonopods in the adult. Not only the exoskeleton is fully differentiated into its different components, like the ventral meta- and pre-sternite and 
meta- and pro-coxa (Figure 5H1), but also internal major organs/apparatuses are fully developed, like the double nerve cord with segmental ganglia (Figure 5H2) (one single suboesophageal ganglion for the gnathal segments, and one for each trunk segment, forcipular segment included). Two smaller ganglia are associated with the two genital segments (data not shown). Circulatory and respiratory systems appear fully functional, at least according to the development of heart and tracheae (Figure 5H3).

\section{Timing of embryoid development}

Figure 6 shows a schematic representation of the stages described above, on a timeline for Strigamia development, with the duration of stages expressed in days, based on my analysis at $13^{\circ} \mathrm{C}$ on single specimens $(\mathrm{n}=23)$ and whole clutches as described in M\&M. The timing of development is probably in part affected by the culturing conditions, in particular if one considers that my specimens have been constantly immersed in mineral oil for three months to reach the adolescens I stage. Additionally, precise timing has been affected by limited observations (frequent observations would have further jeopardized the health of the juveniles, as happens with eggs [6]) and by inter-individual variability, increasingly higher as postembryonic time progresses. Consequently, the reported timing should be mostly useful to perceive the relative duration of the different stages. The only 'natural' case I observed, i.e. the clutch of eggs with their mother of Figure 4G-H (constantly at 13C, undisturbed), fits well with the reported time frame. Indeed, those foetuses, well developed, were observed 90 days after collection (early in the season, very close to deposition time), i.e. at 40 days of post-embryonic development, considering an embryonic development of around 50 days [6].

The overall duration of embryoid development is around 40 days of which the great majority (70\%) is represented by foetus development, with embryoid and peripatoid stages representing, respectively, only $15 \%$ and $10 \%$ of the total duration.

\section{Post-embryonic segmentation}

To check the epimorphic nature of development in Strigamia, in particular the possible post-embryonic addition of leg-bearing segments, I followed 148 specimens from early post-embryonic stages to adolescens I stage (see Materials and Methods for details). 33\% of them could not be used because they either died before reaching adolescens I stage (10\% of the total), or developed abnormalities (like helicomerism) (13\%) or simply the condition of the terminal trunk in the picture would not allow identification of segments (10\%). Almost none (see below) of the juveniles that reached the adolescens I stage $(n=98)$ increased the number of LBS during embryoid development, although the limbs of the last LBS and the following genital segments are indeed added post-embryonically, as described above. The distribution of the final number of LBS was: $4 \%$ with 45 LBS, $45 \%$ with 47 LBS, $47 \%$ with 49 LBS and $4 \%$ with 51 LBS, reasonably close to the distribution of the number of LBS in the wild Brora adult population (see [28]). In 2 cases of proembryoid I, like the specimen shown in Figure 7A-A1, it was impossible to identify traces of segmentation on the cuticle posterior to the 48th LBS, although the latter appears to be normally developed, with the associated limb buds, as expected for that segment at this stage. Once they reached the adolescens I stage, those two individuals had 49 normally developed LBS.

\section{Discussion}

\section{Embryoid stages in Strigamia maritima}

In this work I have analysed, through direct observation on cultured material, the early post-embryonic development of Strigamia maritima, at the time the juveniles are brooded by the mother. Anticipated by the publication of details of epithelium structure [27], I have identified for the first time several previously overlooked moults and clarified the post-embryonic addition of segments (see below). This analysis has allowed me to 1 ) identify in detail a new developmental phase, the proembryoid, further subdivided into three stages, 2) better identify the previously inconsistently described stages of peripatoid and foetus,

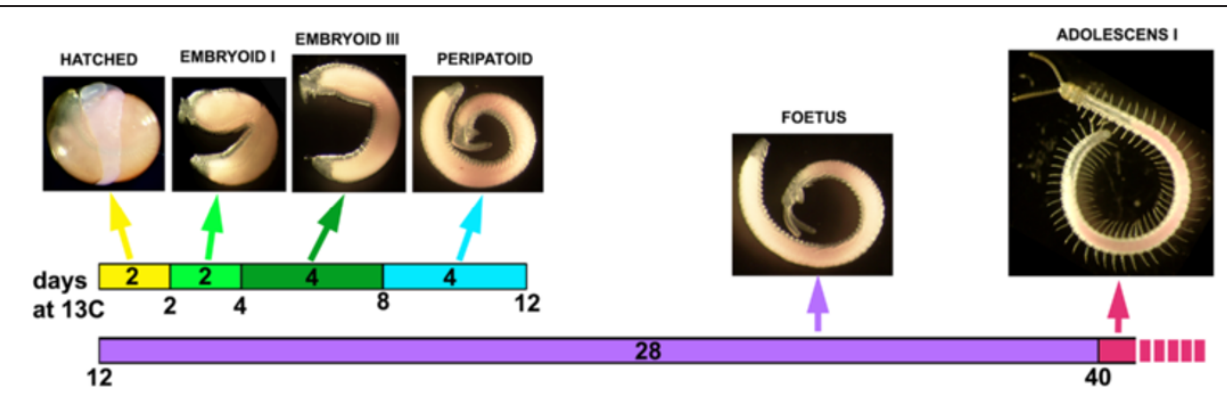

Figure 6 Schematic representation of Strigamia embryoid development. S. maritima development is represented by a series of photographs exemplifying each embryoid stage as indicated. Bars of different colours, are scaled to represent the duration of each developmental stage in days at $13^{\circ} \mathrm{C}$. Under the bars, the approximate cumulative duration in days of the overall developmental period at the end of each stage is indicated. 

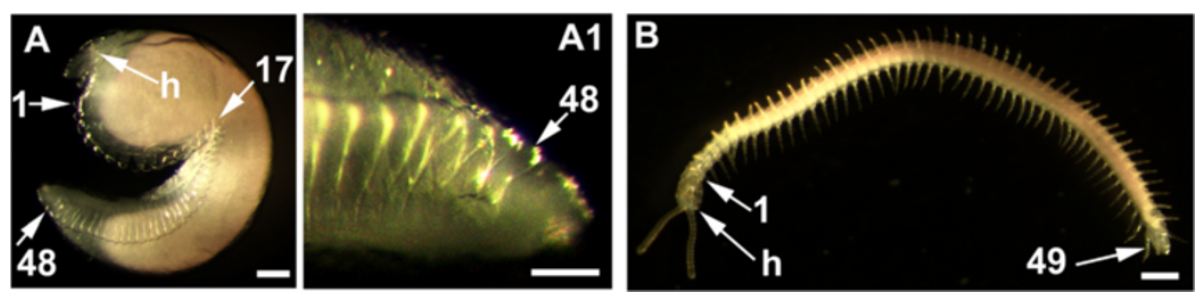

Figure 7 Development of last leg-bearing segment in a single animal. Specimen immersed in mineral oil, still alive in $\mathbf{A}, \mathbf{A} 1$, dead in $\mathbf{B} ; \mathbf{A}$ : Lateral view, B: ventral view. A Strigamia proembryoid I with 48 well-formed limb buds on as many segments; A1: high magnification of the terminal part of the trunk, showing no apparent external segmentation posterior to the 48th LBS. B: same individual as the one in $\mathbf{A}$, at the adolescens I stage, with 49 well formed legs and associated segments, followed by genital segments. Numbers indicate the number of the LBS and associated limb buds; h: head. Scale bars: A: $200 \mu \mathrm{m} ; \mathrm{A1}: 100 \mu \mathrm{m} ; \mathbf{B}: 500 \mu \mathrm{m}$.

and 3) highlight some characters of the following first free-living stage (adolescens I).

I have clearly shown that this first phase of postembryonic development is markedly distinguished from the following phase. In particular, specific embryoid characters can be summarised as follows:

1. There is a gradient in the state of development along the AP axis, where the last segments are still in an 'embryonic' state up to the end of this phase.

2. Not all segments are externally visible (see below for discussion).

3. The way of life is different from the post-embryoid juveniles and adults, with the embryoid juveniles brooded by the mother and relying solely on yolk.

4. Adult structures/organs are not (fully) developed.

It is interesting to note that the main reason why the anamorphic phase of development in more basal centipedes (scutigeromorphs: 6 stages; lithobiomorphs:in general, 5 stages) is traditionally called a 'larva' relies basically only on character 2) above. This 'larva' is already a freeliving juvenile and, somehow, just a small version of the adult, as are post-embryoid stages in Epimorpha centipedes (and indeed this use is disputed by several authors, see [11]). I think the 'embryoid' terminology should be applied also to the scolopendromorphs, as they are characterized by three post-hatching stages brooded by the mother, separated by moults. In Scolopendra, the hatching instar, clearly corresponding to the last embryonic stage as in Strigamia, is called first embryonic stage by Heymons [30] and postembryonic stage I by Dugon et al. [31]. The following two stages, i.e. the proper post-embryonic stages, are called, respectively, second embryonic stage and foetus by Heymons [30], postembryonic stage II and fetus by Dugon et al. [31], and, rather confusingly, third embryonic stage and adolescens I by Lawrence [32] and Brunhuber [33]. It is of course possible that even in this case some moults might have not been recognised, and that the situation might be more complex than it appears.
Consequently, the homology of these stages with those of Strigamia might not be straightforward, although according to their general level of development, it would seem quite plausible that Dugon's [31] postembryonic stage II in Scolopendra could match with Strigamia's peripatoid, and that the foetus in the two species would correspond. Given the extremely limited, and in general dated, literature on centipede development and considering the major differences between the epimorphic model of embryoid and the anamorphic model of 'larva', I consider it unwise at the moment to try to homologise further early post embryonic stages between Epimorpha and the more basal centipedes. Indeed, although Verhoeff [16] called the hatchling of lithobiomorphs, i.e. the first free living instar, 'foetus', there are no reasons to consider that stage specifically homologous to the Epimorpha foetus, and indeed it has been called by more recent authors simply larva I [34,35] or not named at all [36].

The whole embryoid development lasts around 40 days at $13^{\circ} \mathrm{C}$ (probably with a rather high level of variability) representing $80 \%$ of the time it takes for embryonic development at the same temperature [6]. I don't have the exact timing for the natural population in Brora (Scotland), but in natural populations in southern England adolescens I juveniles appear around early August, two months after egg-laying [18]. The shorter developmental time is probably caused by the higher average temperature compared with my culturing conditions. A similar total brooding time of 8 weeks has been reported for the west coast of Norway, near Bergen [9].

The transformation from embryo to free-living adolescens I with the associated drastic elongation is accomplished through 6 moults, although not all of these are accompanied by major morphological changes. The differences between the first stages (hatched stage 8 embryo to peripatoid) are limited, which is expected given the short duration (2-4 days). Nevertheless, there are defined character changes that justify the introduction of my new staging subdivisions, important for their developmental value (the addition and/or maturation of some segments - 
see below) and practically useful for easy identification, a necessary step for a better timing (see Table 1).

The most evident character distinguishing the proembryoid in general from the peripatoid is the $<90^{\circ}$ ventral angle between the anterior and the posterior part of the trunk. This is the remnant of the point of bending of the embryo after dorso-ventral flexure (embryonic stage 6) [6]. We have previously shown that the number of LBS in Strigamia is determined early in embryonic development [29], well before the end of segmentation and at least before dorso-ventral flexure, but possibly much earlier. If the flexure position depends on the positioning along the AP axis, one would have expected LBS values for the bending point reflecting the intraspecific variability and in particular the modal distribution found in the presinking germ bands and in the adults. In fact, the bending point seems to be rather stable, in most cases at 17 LBS, independently from sex and number of leg pairs. From a practical point of view, this means that one cannot use the LBS number at the bending point to estimate the sex of the embryo/proembryoid.

Whatever the initial internal trigger driving the bending in a specific position, the result is that there is for quite some time during development, from embryonic stage 6 to proembryoid III included, a change in the shape of trunk segments positioned at approximately 35\% of the LBS number (considering modal numbers in the adult of either 47 or 49 LBS). This is strikingly similar to the position of the so called 'midbody anomaly', typical of centipede trunk, which in geophilomorphs is rather subtle and is represented by a change in the structure of the otherwise homonomous trunk, at about the two fifths of its length (i.e. 40\%) [37]. I wonder if this phenomenon might be somehow just a by-product of the dorso-ventral flexure in geophilomorphs, although this would be impossible to test directly in Strigamia because the 'anomaly' in this species is altogether absent [37].

Although rather similar to the proembryoid, the peripatoid has a uniform cylindrical trunk. It has still a limited differentiation and sclerotisation of the cuticle and a very limited degree of limb segmentation. Its shape recalls that of an onychophoran, like a Peripatus, from which, indeed, it derives its name.

Of course the cuticle is just a good footprint of the underneath epithelium at the time of hardening, but can be nevertheless used as a convenient developmental snapshot [38]. Indeed, the first shed exuvia, whose apolysis marks the end of embryonic stage 7 , still shows separated bilateral hemitergites (see Figure 1), and consequently is a good marker of the timing of the dorsal closure which must happen during embryonic stage 8 . Ortega-Hernández and Brena [27] have shown that the actual epidermal anatomy, as shown through nuclear staining, is more distinct than the overlaying cuticle for a given stage and subdivision of limbs or appearance of other structures show up much earlier. For example, the complete array of 14 antennomeres is apparently formed already at embryonic stage 8 (see Figure $4 \mathrm{C}$ in [27]), although it will be clearly defined on the cuticle only starting with the proembryoid II and III. By the foetus stage, as shown in detail in [27], all the exoskeletal elements have acquired the characteristic subdivisions, as in the case of the 7 podomeres of the walking legs. The development from embryo to foetus is a rather smooth process, with limited changes in general morphology, although slightly more marked from peripatoid to foetus: this is, of course, correlated with the short duration of the stage. Indeed all the first 4 stages (from hatched embryo 8 to foetus) account for only $30 \%$ of the total embryoid developmental time. In contrast, the foetus itself accounts alone for $70 \%$ of the total duration, and this is correlated with the fact that it is during this stage that the transformation from an embryo-like animal, relying only on yolk, to a free living individual takes place.

In contrast with all previous stages, the adolescens appears to have all the different structures and apparatuses required for independent life, although the large quantity of yolk apparently still available (at least if one considers the pink pigment a good estimate of the yolk content) would indicate that this juvenile is actually able to rely on yolk for quite some time. As in the adult, its relation with the external world will rely on well formed sensilla. In particular, the well developed basiconic sensilla which may be thermohygroreceptors (see [39]) - would have a pivotal function in an animal so sensitive to water loss. Tracheal pits, appearing for the first time during early embryonic stage 7 [6], and further developed during the embryoid stages [27], are now open to the exterior, and the respiratory system should be by now fully functional. The feeding apparatus is likewise completely formed, with the forcipules/maxillipeds fully functional, with the associated venom gland developed (see further Discussion below). Free walking is allowed for the first time by the well sclerotised and partly tanned exoskeleton, specifically articulated into a mature array of sclerites, the result of a specific sequential developmental process during the previous stages, as shown in detail elsewhere [27]. Male gonopods are just appearing on the first genital segment, allowing the assessment of sex in good preparations (see also [20,22,29]). These appendages will require the following juvenile stages to reach full development. Indeed, in particular in these last segments, there are still structures or organs developing further. For example, the coxal pore number of the last pair of legs increases from 1 in the adolescens I to ten in the maturus senior stage [20]. The heart also develops further, not just in size but also in internal organization [9]. 


\section{Forcipule differentiation and evolution}

Probably the main apomorphy of centipedes is the forcipules, a kind of maxillipeds used to grab the prey and inject venom into it. Traditionally, forcipules have been always viewed as resulting from a modification of the first pair of the trunk's walking legs which may be associated early in development with a specific combination or exclusive expression of Hox [40] and wht [41] genes. In comparison with the legs, adult forcipules are formed by a lower number of podomeres, which are named using a modified leg nomenclature, with a clear homology intent (see Figure 3D in [42] for a SEM view of adult Strigamia maritima forcipules). Besides the large basal fused coxosternite, there are 4 articles: a large trochantero-prefemur, a much reduced femur, a tibia and a terminal tarsungulum. Possible evolutionary scenarios have been discussed elsewhere from both a morphological $[42,43]$ and a palaeontological point of view [44]. A detailed analysis of development from embryo to adult has only been done, at least in part, for Scolopendra, where the foetus appears to have the same forcipular articles as the adult [31].

In Strigamia, although the forcipules are already multisegmented by embryonic stage 8 (see also Figure $4 \mathrm{C}$ in [27]), is has been impossible in my material to identify with accuracy the segments forming the forcipule throughout the following stages of development, before it appears well sclerotized in the adolescens I. Surprisingly, in this stage the forcipule seems to have an additional intermediate segment, comparable in size with femur and tibia, for a total of 5 instead of 4 articles (coxosternum excluded). I don't know whether the additional article is really articulated or just a distal modification of the more basal article, but it is interesting to note that, although my material is far from clear, in the previous stage, the foetus, there could be up to 6 segments (Additional file 3: Figure S1). If this subdivision is real, the last two articles would represent the tarsus and the ungulum/claw, later fused to form the tarsungulum, as the evident transverse sulcus in the adolescens I and in Scolopendra [31] would confirm (see [43] for additional evidence and a detailed discussion). With the same argument, the additional intermediate article could be interpreted as a developmental remnant of the prefemur to be fused with the tronchanter, later in development. If that is really the case, this would be a quite straightforward case of recapitulation (as shown by the venom duct development in Scolopendra [31]), although a more detailed analysis, particularly with molecular markers, would be clearly needed to clarify this point.

\section{Embryoid stages in evolutionary scenarios}

According to the most recent phylogenies (e.g. $[45,46])$, longer body with a higher number of segments is a derived character within Myriapoda, expressed by both the
Geophilomorpha within Chilopoda and the Helminthomorpha (which includes several kind of 'long' millepedes, like Platydesmidae and Julidae) within Diplopoda. As myriapods are sequentially segmenting arthropods, an increase in the number of segments implies an extension of the segmentation time. This is achieved in Helminthomorpha by extending, in some species indefinitely, the postembryonic addition of segments that was probably typical of the myriapod ancestor, and by the Geophilomorpha by protracting, and possibly accelerating, the embryonic phase of segment addition. The delaying of complex organogenesis and further development of the body to early post-embryonic stages (embryoid stages) might have been a necessary consequence of this exploitation of the segmentation patterning machinery during embryonic time. In this sense, I think that Strigamia embryoids, brooded by the mother for a considerable time, could be considered nothing more than an 'extended embryonic phase'. Although probably the results of different evolutionary pressures, a newborn embryoid-like, i.e. not free-living and not fully developed, as are Strigamia embryoids, is actually present in many arthropod clades, and is indeed common to many myriapods, where one or two such stages are found and are called pupoid in Diplopoda and Pauropoda, and prelarva in Symphyla (see $[5,11]$ for a detailed general comparative discussion).

This is arguably a case of heterochrony. Indeed, in Strigamia, as the embryonic development seems to have extended across the post-embryonic divide, on the contrary it would seem that some moulting cycles possibly link to more ancestral post-embryonic development than might have been anticipated, and then condensed. This could provide a possible explanation for the frequent moults of Strigamia embryoid instars (but see also Discussion below), so closely packed that the second and third moults happen almost simultaneously. This is not a unique case, and indeed the simultaneous shedding of multiple cuticles (associated with 'virtual stages') has been observed, for example, in some leiodid beetles and some phorid flies, insects with extremely abbreviated development (see [11]), a clear situation of 'condensation' of more ancestral stages.

\section{The residual anamorphic nature of Strigamia post-embryonic development}

Lacking a direct analysis of early post-embryonic development, geophilomorphs and scolopendromorphs have been always considered epimorphic, commonly reported as having all body segments and all legs present at hatching. In this work I have shown that this is not strictly the case, as in the first post-embryonic stage(s) not all segments are present, because the genital segments are not formed yet (see below), and not all legs are present, because the last LBS is limbless. Additionally, my analysis has shown 
that a small fraction (2 out of 98 specimens) of specimens fail to show on the cuticle traces of the last LBS, although this condition may be the result of the low quality of the live material or an artefact of the culturing conditions (although the resulting adolescens I were actually normally developed).

The last LBS is in general molecularly determined already at embryonic stage 7 at the level of expression of the gene engrailed (en) [27]. This leaves open the possibility that the lack of external appearance of the last LBS is the result of a delay into postembryonic time either of the actual initial molecular patterning, or, at the very least, of the gross epidermal morphology of the segment at the moment of the formation of the cuticle.

Certainly, posterior to the last LBS, the 2 last segments, i.e. the genital segments, are added post-embryonically, apparently sequentially, and appear well defined externally only with the last embryoid stage, the foetus.

The interpretation of how many genital segments are present in Chilopoda is a matter of discussion. I here consider them two, as most authors maintain, relying on the presence of 2 genital nervous ganglia (in the adult, smaller than the LBS ones; Brena, unpublished data). Indeed, morphologically, the boundaries of the genital segments are unclear in my foetus material, but are already too complex in the adolescens I. There are no additional en stripes after the last LBS in embryo 8 of Strigamia, and attempts to mark with the gene en post-embryonic stages and, hence, the appearance of the genital segments, have failed [27].

In conclusion, the last LBS can appear, at least externally, post-embryonically and the genital segments are both determined molecularly and appear morphologically postembryonically. For this reason Strigamia (and possibly also all Epimorpha) is not fully epimorphic.

\section{The variable nature of segmentation across development and evolution}

We have previously shown that most segments in geophilomorphs are initially produced by an early double segment patterning system, operating through oscillation of expression of genes like even-skipped, activated at the posterior of the germ band [4]. This initial pair-rule system is not present in other studied myriapods such as the centipede Lithobius [36] and the millipede Glomeris [47]; consequently, we hypothesised that this pair rule system could have facilitated the formation of the much higher number of segments typical of geophilomorphs. Nevertheless, the last 8 leg-bearing segments or so are patterned differently, at single segment periodicity with no indication that the whole tissue is undergoing dynamic cycles of gene expression [4]. It is possible that this final phase of segment addition depends on a progressive wave of spatial patterning that is triggered by signals emanating from the maturing segments that it leaves behind. Patterning by such a progressive front would be a fundamentally different mechanism from the clock-like process of posterior oscillation, but both share the characteristic feature that, at the level of genetic control, they are intrinsically repetitive processes, requiring the same set of gene interactions to make each segment. Either would allow indefinite sequential repetition, to make a trunk of indeterminate length. It is possible, though, that local signalling might be more easily initiated and repressed in co-ordination with the moult cycle than would early global oscillation, where cell-cell coordination may be based on Notch-signalling [4]. Such late co-ordination with the moulting cycle would almost certainly have characterised segment addition during post-embryonic trunk elongation in ancestral arthropods and may still do so in most myriapods during their anamorphic segmentation phase, including, perhaps, the residual 'anamorphic' phase of genital segments formation in Strigamia.

In this context, the early embryoid of Strigamia moults frequently, perhaps more as a byproduct of the periodic expression of ecdysone, involved originally in the hormonal regulation of the last phases of segmentation. Note that, at least in insects, not only morphogenetic processes and cuticle deposition but also elongation and segmentation of the germ band may be regulated by ecdysteroids present in the yolk [48-50]: in this sense, Strigamia's persistent and abundant yolk may have not only a nutritional function, but also a timing regulatory function across both embryonic and embryoid time.

If the formation of the genital segments may fully represent a vestigial anamorphic phase of segmentation in Strigamia, the formation of the last LBS appears to represent the transition from the last phase of embryonic segmentation (the last 8 segments or so) [4] to post-embryonic segmentation. Indeed, the last LBS are molecularly patterned before the first embryonic moult [27], but morphologically appear only after it [6], or even, in some rare cases, postembryonically altogether [this article].

In other words, there appears to be somehow a continuum in the segmentation process across the different developmental stages of Strigamia, mid-embryonic, late embryonic, and post-embryonic included. This, in turn, illustrates the variability of the segmentation process which may significantly concur to its evolvability, as exemplified by the shift from anamorphic to epimorphic development that has characterized the evolution of these myriapods.

\section{Materials and methods}

Strigamia maritima eggs were collected from a previously studied population near Brora (NE Scotland). Individual clutches of eggs were taken to the laboratory, and cultured at $13^{\circ} \mathrm{C}$, in most cases under a shallow layer of mineral oil (Sigma M8410, embryo tested), but, occasionally, in LES (Locust Embryo Saline) buffer, as described in [6]. 
Under these conditions, Strigamia eggs can develop, hatch and develop further to the adolescens I stage, more than 2 months after collection [22].

For the description of development I used 23 specimens from 7 clutches collected in June 2009, which I followed individually as they developed, photographing each embryoid every two days initially, and then every time I identified a change in development (e.g. an ecdysis). As we did for the embryonic stages [6], I compared the timing of these specimens to estimate the average duration of development for each embryoid stage. I compared and confirmed this estimate by tracking the embryoid development of 5 clutches collected in June 2010, followed as a whole. For the experiment aimed at checking the possible postembryonic addition of segments I used 148 hatched and very early embryoid juveniles collected as eggs in June 2010. I photographed them at the beginning, at mid embryoid stages (proembryoid III or peripatoid stage) and then at the adolescens I stage, limiting interference as much as possible, to reduce any effect that this might have on development rate and survival (as shown, at least for embryonic development, by [6]). In one single case, I was able to collect in the field a clod of substrate which included a brood chamber containing the mother with her clutch of eggs and kept it in a wet chamber in culture at $13^{\circ} \mathrm{C}$ up to the foetus stage (see Figure 4G-H).

After hatching, the chorion and the following exuviae tend to stay attached to the posterior end of the animal up to the foetus stages, at least in cultured specimens (see $[5,7,21]$. To better identify the morphology of the different stages, chorion and exuviae were manually removed with fine tweezers from some of the live specimens (see Figures $2 \mathrm{AB}$ and $3 \mathrm{~A}$ ).

In some of my first experiments, eggs were cultured on filter paper moistened with LES. These specimens were photographed with the live animal immersed in LES (see e.g. Figure $1 \mathrm{~A}, \mathrm{~B}, \mathrm{C})$. Cultured like this, the chorion and the exuviae (at least the first one) tend to detach from the animal (see Figure 1C). However, under these conditions I was not able to keep specimens alive for more than a few days after hatching.

Pictures of whole juvenile specimens and whole clutches (see Figure 4G-H) were taken using a Leica MZFLIII stereomicroscope with a Leica DFC 500 Camera (and Leica Firecam software), using lateral light and, generally, a black background. Flat mounted preparations of unfixed specimens were prepared as described in [22] and photographed with a Zeiss Axiophot compound microscope (Zeiss, Jena, Germany) with a Leica FC3 FX camera. Contrast and colour of the photos were adjusted using Adobe Photoshop. Stacks of images at multiple focal depths were combined with Helicon Focus software (Helicon Soft Ltd., Kharkov, Ukraine).

\section{Additional files}

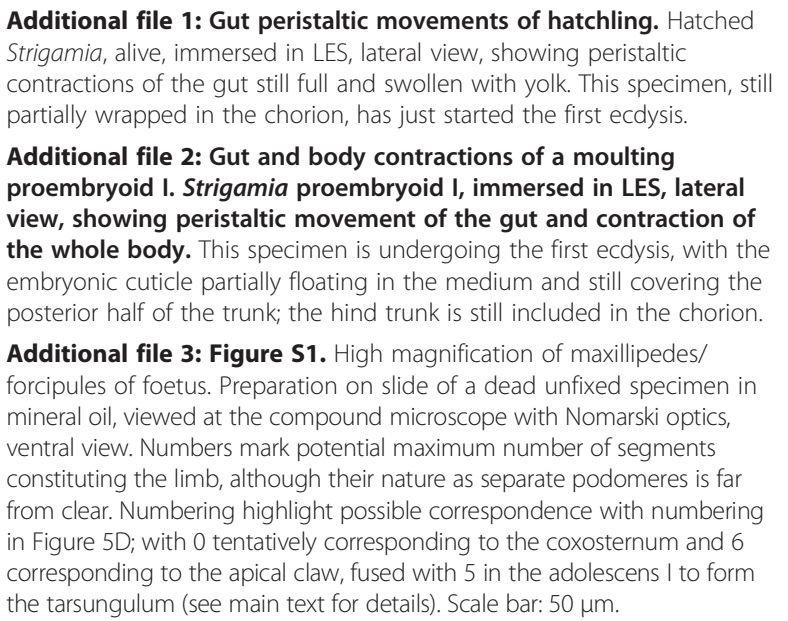

Abbreviation

LBS: Leg bearing segment.

\section{Competing interests}

The author declares that he has no competing interests.

\section{Acknowledgements}

The author wishes to thank Javier Ortega-Hernández for kindly providing 3D and $4 \mathrm{D}$ figures, Michael Akam for providing laboratory space, facilities and freedom of research, and valuable comments on a early version of the draft, and Wallace Arthur, Giuseppe Fusco, Alessandro Minelli and an anonymous referee for very helpful comments on the draft; the author is particularly grateful to Giuseppe Fusco for providing a solution for the nomenclature of the early post-embryonic stages. This work was funded by BBSRC grant No. BBS/B/07519 to Michael Akam, and by a University of Cambridge Value in People award to CB.

Received: 18 March 2014 Accepted: 1 August 2014

Published: 13 August 2014

\section{References}

1. Edgecombe GD, Giribet G: Evolutionary biology of centipedes (Myriapoda: Chilopoda). Annu Rev Entomol 2007, 52:151-170.

2. Chagas-Júnior A, Edgecombe GD, Minelli A: Variability in trunk segmentation in the centipede order Scolopendromorpha: a remarkable new species of Scolopendropsis Brandt (Chilopoda: Scolopendridae) from Brazil. Zootaxa 2008, 1888:36-46.

3. Schileyko AA: Redescription of Scolopendropsis bahiensis (Brandt, 1841), the relations between Scolopendropsis and Rhoda, and notes on some characters used in scolopendromorph taxonomy (Chilopoda: Scolopendromorpha). Arthropoda Sel 2006, 15:9-17.

4. Brena C, Akam M: An analysis of segmentation dynamics throughout embryogenesis in the centipede Strigamia maritima. BMC Biol 2013, $11: 112$.

5. Minelli A, Brena C, Deflorian G, Maruzzo D, Fusco G: From embryo to adult-beyond the conventional periodization of arthropod development. Dev Genes Evol 2006, 216:373-383.

6. Brena C, Akam M: The embryonic development of the centipede Strigamia maritima. Dev Biol 2012, 363:290-307.

7. Weil E: Zur Biologie der einheimischen Geophiliden. Z Angew Ent 1958, 42:173-209.

8. Prunescu C, Capuse I: Nouvelles données sur le début du développment postembryonnaire chez les myriopodes de l'ordre Geophilomorpha. Trav Mus Hist Nat Gr Antipa 1971, 11:111-119.

9. Økland S: Changes in heart ultrastructure during development of Strigamia maritima Leach (Myriapoda, Chilopoda, Geophilidae). Int J Insect Morphol Embryol 1984, 13:233-245. 
10. Lewis JGE: The Biology of Centipedes. Cambridge: Cambridge University Press; 1981.

11. Minelli A, Fusco G: Arthropod post-embryonic development. In Arthropod Biology and Evolution. Edited by Minelli Boxshall G, Fusco G. Berlin: Springer; 2013:91-122.

12. Newport G: Monograph of the Class Myriapoda, Order Chilopoda; with observations on the general arrangement of the Articulata. Trans Linn Soc Lond 1844, 19:265-302.

13. Latzel R: Die Myriopoden Der Österreichisch-Ungarischen Monarchie: Die Chilopoden, Volume 1. Wien A. Hölder; 1880.

14. Sograff N: Materialen zur Kenntnis der Embryonalentwicklung von Geophilus ferrugineus L. K. und Geophilus proximus L. K. Nachr Ges Freunde Naturkunde Anthr Ethnol Moskau 1883, 43:1-77.

15. Metschnikoff E: Embryologisches über Geophilus. Z Wiss Zool 1875, 25:312-322

16. Verhoeff KW: Myriapoda. In Klassen Ordnungen Tierreiches. Volume 5. Edited by Bronn HG. Leipzig: Akademische Verlagsgesellschaft; 1902 [vol. 2].

17. Lewis JGE: The Life History and Ecology of the Littoral Centipede Strigamia Maritima (Leach). PhD Thesis. London: University of London; 1960.

18. Lewis JGE: The life history and ecology of the littoral centipede Strigamia (=Scolioplanes) maritima (Leach). Proc Zool Soc Lond 1961, 137:221-248.

19. Johnstone J, Arthur W: Observations on the eggs and early postembryonic stages of Strigamia maritima. Bull Brit Myr Iso Group 2002, 18:33-40.

20. Horneland EO, Meidell BA: Postembryonic development of Strigamia maritima (Leach, 1817) (Chilopoda: Geophilomorpha: Linotaeniidae) with emphasis on how to separate the different stadia. Soil Org 2009, 81:373-386.

21. Vedel V, Arthur W: Character changes during the early post-embryonic development of the centipede Strigamia maritima (Leach, 1817) (Chilopoda: Geophilomorpha). Int J Myriapodology 2009, 2:53-61.

22. Vedel V, Apostolou Z, Arthur W, Akam M, Brena C: An early temperaturesensitive period for the plasticity of segment number in the centipede Strigamia maritima. Evol Dev 2010, 12:347-352.

23. Archey G: Revision of the Chilopoda of New Zealand. Rec Auckl Mus 1936, 2:43-70.

24. Misioch M: Variation of characters in some geophilid chilopods. Abh Verhandlungen Naturwissenschaftlichen Ver Hambg 1978, 21/22:55-62.

25. Minelli A: Post-embryonic development and the phylogeny of geophilomorph centipedes (Chilopoda). Bijdr Dierkd 1985, 55:143-148.

26. Horneland EO, Meidell BA: The epimorphosis of Strigamia maritima (Leach, 1817) (Chilopoda: Geophilidae). Insect Syst Evol 1986, 17:127-129.

27. Ortega-Hernández J, Brena C: Ancestral patterning of tergite formation in a centipede suggests derived mode of trunk segmentation in trilobites. PloS One 2012, 7:e52623.

28. Kettle C, Arthur W: Latitudinal cline in segment number in an arthropod species, Strigamia maritima. Proc R Soc Lond Ser B-Biol Sci 2000, 267:1393-1397.

29. Brena C, Green J, Akam M: Early embryonic determination of the sexual dimorphism in segment number in geophilomorph centipedes. EvoDevo 2013, 4:1-9.

30. Heymons R: Die Entwicklungsgeschichte der Scolopender. Zool Stuttg 1901, 13:1-244.

31. Dugon MM, Hayden L, Black A, Arthur W: Development of the venom ducts in the centipede Scolopendra: an example of recapitulation. Evol Dev 2012, 14:515-521.

32. Lawrence RF: Some observations on the post-embryonic development of the Natal Forest Centipede, Cormocephalus multispinus (Kraep.). Ann Natal Mus 1947, 11:139-156.

33. Brunhuber BS: Egg laying, maternal care and development of young in the scolopendromorph centipede, Cormocephalus anceps anceps Porat. Zool J Linn Soc 1970, 49:225-234

34. Scheffel H: Untersuchungen über die hormonale Regulation von Häutung und Anamorphose von Lithobius forficatus (L.) (Myriapoda, Chilopoda). Zool Jahrb Abt Allg Zool Physiol Tiere 1969, 74:436-505.

35. Voigtländer K: The life cycle of Lithobius mutabilis L. Koch, 1862 (Myriapoda: Chilopoda). Bonn Zool Beitr 2006, 55:9-25.

36. Hughes $C L$, Kaufman TC: Exploring myriapod segmentation: the expression patterns of even-skipped, engrailed, and wingless in a centipede. Dev Biol 2002, 247:47-61.

37. Eason EH: Centipedes of the British Isles. London: Warne; 1964.

38. Fusco G, Brena C, Minelli A: Cellular processes in the growth of lithobiomorph centipedes (Chilopoda: Lithobiomorpha). A cuticular view. Zool Anz 2000, 239:91-102.
39. Minelli A: Chilopoda. In Microsc Anat Invertebr Vol 12 - Onychophora Chilopoda Lesser Protostomata. Edited by Harrison FW. New York: Wiley-Liss; 1993:57-114.

40. Brena C, Chipman AD, Minelli A, Akam M: Expression of trunk Hox genes in the centipede Strigamia maritima: sense and anti-sense transcripts. Evol Dev 2006, 8:252-265.

41. Hayden $L$, Arthur W: Expression patterns of Wnt genes in the venom claws of centipedes. Evol Dev 2013, 15:365-372.

42. Dugon MM, Black A, Arthur W: Variation and specialisation of the forcipular apparatus of centipedes (Arthropoda: Chilopoda): A comparative morphometric and microscopic investigation of an evolutionary novelty. Arthropod Struct Dev 2012, 41:231-243.

43. Maruzzo D, Bonato L: Morphology and diversity of the forcipules in Strigamia centipedes (Chilopoda, Geophilomorpha). Arthropod Struct Dev 2014, 43:17-25.

44. Haug JT, Haug C, Schweigert G, Sombke A: The evolution of centipede venom claws - Open questions and possible answers. Arthropod Struct Dev 2014, 43:5-16.

45. Shear WA, Edgecombe GD: The geological record and phylogeny of the Myriapoda. Arthropod Struct Dev 2010, 39:174-190.

46. Miyazawa H, Ueda C, Yahata K, Su Z-H: Molecular phylogeny of Myriapoda provides insights into evolutionary patterns of the mode in post-embryonic development. Sci Rep 2014, 4:4127.

47. Janssen R, Budd GE, Prpic NM, Damen WG: Expression of myriapod pair rule gene orthologs. EvoDevo 2011, 2:5

48. Lanot R, Dorn A, Gunster B, Thiebold J, Lagueux M, Hoffmann JA: Functions of ecdysteroids in oocyte maturation and embryonic development of insects. In Ecdysone from Chemistry to Mode of Action. Edited by Stuttgart KJ. Georg Thieme; 1989:262-270.

49. Chávez VM, Marqués G, Delbecque JP, Kobayashi K, Hollingsworth M, Burr J, Natzle JE, O'Connor MB: The Drosophila disembodied gene controls late embryonic morphogenesis and codes for a cytochrome P450 enzyme that regulates embryonic ecdysone levels. Development 2000, 127:4115-4126.

50. Sonobe H, Yamada R: Ecdysteroids during early embryonic development in silkworm Bombyx mori: metabolism and functions. Zoolog Sci 2004, 21:503-516

\section{doi:10.1186/s12983-014-0058-9}

Cite this article as: Brena: The embryoid development of Strigamia maritima and its bearing on post-embryonic segmentation of geophilomorph centipedes. Frontiers in Zoology 2014 11:58.

\section{Submit your next manuscript to BioMed Central and take full advantage of:}

- Convenient online submission

- Thorough peer review

- No space constraints or color figure charges

- Immediate publication on acceptance

- Inclusion in PubMed, CAS, Scopus and Google Scholar

- Research which is freely available for redistribution 